BIOKEMISTRI 19(1):23-28 (June 2007)

This article is downloadable online in PDF

format at http://www.bioline.org.br/bk

Printed in Nigeria
An international journal published by the

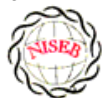

Orgerian Society for E̊xperimental Siology

\title{
Preliminary investigation into the possible endocrine disrupting activity of Bonny light crude oil contaminated - diet on Wistar albino rats
}

\section{Olawale OTITOJU ${ }^{1 *}$ and Ikechukwu N. E. ONWURAH ${ }^{2}$}

\author{
${ }^{I}$ Department of Biochemistry, Kogi State University, P M B 1008 Anyigba, Kogi State, Nigeria \\ ${ }^{2}$ Dept of Biochemistry, Pollution Control Unit, University of Nigeria, Nsukka, Enugu State, Nigeria
}

Received 16 August 2006

MS/No BKM/2006/028, (c) 2007 Nigerian Society for Experimental Biology. All rights reserved.

\begin{abstract}
Many chemicals have recently been demonstrated to be Endocrine-disrupting compounds and may potential interfere with normal reproductive processes. In this study, we quantified the effect of Bonnylight crude oil contaminated diet on Wister albino rats. Forty-five rats (twenty male and twenty five females) were expose to Bonny -light crude oil contaminated diet at concentrations of $1 \%, 5 \%$ and $10 \%$ $(\mathrm{w} / \mathrm{w})$. Throughout the experiment, we observed $20 \%$ reduction in fecundity in the $1 \%$ experimental group but in 5\% experimental group, it was observed that there was a $45 \%$ reduction in fecundity when compared with parallel control group. However, the $10 \%$ group did not liter at all. There was a significant increase $(p<0.05)$ in the testosterone level of male rats fed with $1 \%$ contaminated diet but the testosterone level of $5 \%$ and $10 \%$ treated group showed a significant reduction $(p<0.05)$. The estrogen level in the female rats showed a general significant increase $(p<0.05)$ in all the groups when compared with the female control group. This preliminary result suggest that Bonny-Light crude oil may have the potential to alter reproductive activity and hence a possible endocrine disruptor.
\end{abstract}

Keywords: Endocrine disruptors, Reproductive, Bonny-light crude oil, fecundity

*To whom correspondence may be addressed, E-mail: iyknuelo@yahoo.com, otitojuolawale@yahoo.com Tel: 08033622480 


\section{INTRODUCTION}

We are routinely exposed to a lot of environmental pollutants such as pesticides, fertilizers, crude oil or any of its fractions on a daily basis. These pollutants have been implicated in causing many biochemical and toxicological effects on aquatic and terrestrial animals ${ }^{1}$. Although, various research work have been carried out on crude oil, very few has been directed to study the impact of crude oil on the endocrine system.

A number of chemicals with the capacity to disrupt the endocrine and reproductive systems are now widespread in the environment ${ }^{2}$. These chemicals are generally called endocrine disruptors. They consist of synthetic and naturally occurring chemicals that affect the balance of normal hormonal functions in animals including humans ${ }^{3}$. In the past few years, numerous effects of endocrine disrupting compounds (EDCs) have emerged, including intersexes of riverine fish, reproductive failure and abnormalities in marine invertebrates, birds, alligators and polar Bears ${ }^{4}$.

However, in many developing nations, little or no attention is given to research of this magnitude to determine their Impacts on the environment and elucidating the possible health effect it might caused. One could imagine the bewildering effects this might pose over a long period of exposure and even the transgenerational effects.

The purpose of this study was to investigate the effects of sub-chronic exposure of Bonny-Light crude oil on reproductive capacity (fecundity) and to ascertain the possible endocrine disrupting effects on Wister rats fed with contaminated feed (Growers' Marsh).

\section{MATERIALS AND METHODS}

Fourty five rats aged 15-17 weeks and weighing 93.6-140.8g were obtained from the Faculty of Veterinary Medicine, University of Nigeria, Nsukka (UNN). They were acclimatized for two weeks at the Animal House of Department of
Biochemistry, UNN. The rats were randomly allocated to four groups. Each group consisted of eleven rats ( 4 males, 7 females). These groups are: $0.0 \%(w / w)$ no contamination (control), $1.0 \%(w / w)$ crude oil contaminant, $5.0 \%(w / w)$ crude oil contaminant, $10.0 \%(w / w)$ cruude oil contaminant. Crude oil was obtained from the terminal of Nigerian Petroleum Development Commission/AGIP, OPKOHO Well 4.

\section{Feed formulation}

Commercial Poultry feed was contaminated with crude oil by weighing out a definite amount of the feed and then mixed with the crude oil to give $1 \%, 5 \%$ or $10 \%(w / w)$ contamination. The feed for control group did not contain crude oil.

\section{Hormonal assays}

Reproductive hormones such as follicle simulating hormone (FSH) Lutinizing hormone (LH), Estrogen, Testosterone, Prolacting and progesterone were determined by Enzyme immunoassay method, using commercially available kits by Syntron Bioresearch, Inc U.S.A.

\section{Fecundity}

The reproductive capacity of the animals was determined by counting the litter size and the number of survivors. However, variation in the gestational period was also noted.

\section{RESULTS}

During the twenty-eight days' exposure period, the mean weekly weight and daily feed consumption was determined (Table 1). The result showed that there was no significant decrease $(P>0.05)$ in the body weight of rats when compared with the parallel control group. However, the daily feed consumption of rats decreased significantly $(P<0.5)$ when compared with the control group (Table 1).

Fecundity; measured as the average litter size per group was found to decrease generally in the experimental groups (Table 2). This decrease was not significant $(P>0.05)$ in the $1 \%(w / w)$ group, which recorded $20 \%$ decrease when compared with the parallel control. The 5\% $(w / w)$ group showed significant decrease $(P<$. 
$0.05)$ of $45 \%$ but the $15 \%(w / w)$ group did not liter at all. However, the experimental groups showed delayed gestation period with the $1 \%$ $(w / w)$ group having the least delay period of 15 days while the $5 \%$ group displayed 23 days delayed gestational period (Table 2).

Table 1: Weights and daily feed consumption of rats

\begin{tabular}{|c|c|c|c|}
\hline GROUP & $\begin{array}{l}\text { WEEKLY WEIGHT } \\
\text { (g/group/week) }\end{array}$ & OF RATS & FEED CONSUMPTION (g/group/day) \\
\hline CONTROL & $166.30 \pm 17.51$ & & $128.10 \pm 21.26$ \\
\hline $1 \%$ & $138.30 \pm 10.71$ & & $43.36 \pm 7.44$ \\
\hline $5 \%$ & $140.27 \pm 2.19$ & & $39.57 \pm 11.06$ \\
\hline $10 \%$ & $132.60 \pm 15.56$ & & $21.86 \pm 9.66$ \\
\hline
\end{tabular}

Results are mean $\pm \mathrm{SD}(\mathrm{N}=7)$

Table 2: Fecundity result of rats fed with crude oil contaminated diet

\begin{tabular}{lllllllllll}
\hline GROUP & 1 & 2 & 3 & 4 & 5 & 6 & 7 & Litter size & Total survival & \% Survival \\
\hline Control & 9 & 9 & 7 & 8 & 9 & 7 & 7 & 56 & 47 & 83.93 \\
$1 \%$ & 6 & 7 & 7 & 8 & 6 & 5 & 6 & 45 & 16 & 35.56 \\
$5 \%$ & 7 & 5 & 5 & 4 & 6 & 4 & - & 31 & 7 & 22.58 \\
$10 \%$ & - & - & - & - & - & - & - & - & 0 & 0.00 \\
\hline
\end{tabular}

Results are mean $\pm \mathrm{SD}(\mathrm{N}=4)$

Table 3: Male hormone result

\begin{tabular}{lllll}
\hline GROUP & $\mathrm{T}_{4 \mathrm{ng} / \mathrm{ml}}$ & $\mathrm{LH}_{\mathrm{mIU}}$ & $\mathrm{FSH}$ & $\mathrm{PRL}_{\mathrm{ng} / \mathrm{ml}}$ \\
\hline Control & $0.41 \pm 0.01$ & $10.10 \pm 0.02$ & $4.00 \pm 0.01$ & $9.62 \pm 0.01$ \\
$1 \%$ & $1.40 \pm 0.01$ & $4.90 \pm 0.01$ & $3.70 \pm 0.02$ & $5.30 \pm 0.01$ \\
$5 \%$ & $0.12 \pm 0.02$ & $9.90 \pm 0.01$ & $3.30 \pm 0.01$ & $9.40 \pm 0.03$ \\
$10 \%$ & $0.30 \pm 0.01$ & $5.20 \pm 0.02$ & $3.00 \pm 0.01$ & $9.60 \pm 0.01$ \\
\hline
\end{tabular}

Results are mean $\pm \mathrm{SD}(\mathrm{N}=4)$

Table 4: Female hormone result

\begin{tabular}{llllll}
\hline GROUP & LH $_{\mathrm{mIU}}$ & $\mathrm{FSH}$ & $\mathrm{PRL}_{\mathrm{ng} / \mathrm{ml}}$ & $\mathrm{P}_{4}$ & $\mathrm{E}_{2}$ \\
\hline Control & $4.70 \pm 0.01$ & $3.12 \pm 0.01$ & $10.30 \pm 0.01$ & $20.02 \pm 0.02$ & $550.00 \pm 16.00$ \\
$1 \%$ & $9.90 \pm 0.02$ & $3.71 \pm 0.01$ & $9.40 \pm 0.01$ & $26.20 \pm 0.01$ & $1130.0 \pm 10.52$ \\
$5 \%$ & $4.40 \pm 0.02$ & $3.42 \pm 0.01$ & $5.12 \pm 0.01$ & $11.00 \pm 0.01$ & $1060.5 \pm 1.70$ \\
$10 \%$ & $11.5 \pm 0.02$ & $3.90 \pm 0.01$ & $10.70 \pm 0.02$ & $24.50 \pm 0.02$ & $1650.7 \pm 10.11$ \\
\hline
\end{tabular}


Table 3 showed the hormonal assay results. The testosterone level showed a significant increase $(P<0.05)$ in the $1 \%$ group, but the 5\% and 10\% groups showed decrease testosterone levels and this decrease was not significant at $(P>0.05)$.

The LH and FSH were found to generally decrease in the male groups at different concentrations tested, but this decrease was not significant $(P>0.05)$. The female groups showed increase in FSH and LH (Table 4). Estrogen level was also found to significantly increased $(P<0.05)$ when compared with parallel control group.

\section{DISCUSSION}

Crude oil is a complex mixture of many different components. Its exploration and transportation has generated a lot of environmental problems, especially in developing nations. It is note worthy, that the devastating consequences of crude oil spill in the Niger Delta of Nigeria may pose great hazards on both aerial and terrestrial environments.

Accumulating scientific data have shown that many man-made and naturally occurring compounds released frequently into the environment have adverse effects on the endocrine system of humans and wildlife ${ }^{5}$. Some of these endocrine-disrupting chemicals (EDCs) affect the endocrine system because of their ability to mimic natural estrogen, whereas others may function as anti-estrogen ${ }^{6}$. A number of environmental chemicals have been identified as endocrine disruptors, and their unwanted effects on our lives have become serious problems all over the world. At present, the adverse effects on endocrine systems in animals have resulted in reproductive malfunction and developmental disorders ${ }^{7}$.

The finding of our study has shown that crude oil contaminated diet could pose serious effect on the hormonal system, which may consequently affect the reproductive process in organisms found in crude oil polluted environment including humans. The bioaccumulation of crude oil residues in the ecosystem over a long period of time may lead a lot of health problems if adequate care is not taking.

Endocrine disruptors as their named implied, may include many fractions of crude oil such as the polycyclic aromatic hydrocarbons (PAHs). Like all other crude oil, Bonny light crude oil contain PAHs which has the potential to generate reactive oxygen species ${ }^{8}$. PAHs have also being implicated in possessing antiestrogenic activity 9

The results of this study also highlight the potential susceptibility of exposed organisms to toxic injury as a result of crude oil intake via water, food or inhalation. Body weights, of rats decreased in the experimental groups fed with crude oil contaminated diet, the reduction in weight may be attributed to the low consumption rate among these groups. This may be due to the unpalatability of the feed and consequently a lot of protein, DNA and lipid oxidation may have taken place in the system of the rats.

The endocrine system controls many functions of the body, any disruption to this system may cause changes in reproduction, development, growth or behaviour that can affect the animals or humans or their offspring ${ }^{10}$. Testosterone levels as measured in the male rats showed a significant increase in the $1 \%$ treated group. This increase may be of great importance in spermatogenesis, male pattern behaviour etc.

According to Monosson et al. ${ }^{11}$, anti-androgens in adult animals increase the serum levels of androgens, LH and estrogens. This may imply that the crude oil is acting as anti-androgenic compounds, and thereby inducing spontaneous abortions, stillbirths and reproductive malfunction $^{12}$

The estrogen level showed significant increase in the female rats. This hormone function in many ways by stimulating the development of tissues involve in reproduction. The increase estrogen level may also increase the sexual activities of female rats as evidenced in our observation of their willingness to accept the males, as well as even mounting themselves (female - female). This observation may have a 
serious implication because a lot of energy may be channeled into sexual activity and not into effective reproductive activity.

However, the interaction between the low level of testosterone and the high level of estrogen may be responsible for the observed delay in gestation among the groups $1 \%, 5 \%$ and $10 \%$ $(w / w)$, as the male rats may have low sperm count or abnormal sperm morphology. This observation agreed with the earlier observation by Doyle and Lim who observed that certain environment chemicals are capable of mimicking or modulating the effects of gonadal hormones, thereby potentially interfering with the reproductive morphology and behaviour of an organism ${ }^{13}$.

We also observed slight effects on fecundity and survival of rats exposed to various concentrations of crude oil contaminated diet. The greatest effect was on the $10 \%$ treated group where no fecundity was recorded. This gives a vivid evidence of the effect on the reproductive system. Therefore, we suggest that the observed decrease or increase in serum hormone may be as a result of the possible estrogenic or androgenic property of crude oil and have a direct association with reproduction.

Hormones act at extremely low levels (part per trillion) therefore, in theory, even exposure to low levels of hormonally active agents such as crude oil may be of major health concern, particularly during sensitive periods of fetal development. Furthermore, endocrine-mediated effects may be subtle and manifest primarily in populations rather than in individuals. For example, slight overall declines in sperm density or intelligent quotient may have little relevance for an individual but important adverse implication for the population ${ }^{14}$. However, lowlevel exposures to endocrine-disrupting chemical are ubiquitous in today's environment. The ubiquitous nature of the exposures combined with nontrivial potential health effects justifies further research, education and preventive action to reduce human exposures to crude oil as a possible endocrine disruptor. This preliminary results suggest that bonny-light crude oil may have the potential to alter reproductive activity and hence a possible endocrine disruptor.

\section{REFERENCES}

1.Ovuru, S. S. Berepubo, N. A and Nodu M. B. (2004) Biochemical blood parameters in semi-adult rabbits experimentally fed crude oil contaminated diets. Afr. J. Biotechnol. 3:343-345.

2.Colbborn, T., Vom saal, F.S. and Soto, A.M. (1993) Developmental effects of endocrine disrupting chemical in wildlife and humans. Environ. Hlth. Perspect. 101:378-384.

3.McClellan-green, P.D (2003) Mechanism of endocrine disruption in invertebrates: Looking beyond steroid hormones. SETAC Globe 4:37-40.

4.Maczka, C., Pang, S., Policansky, D. and Wedge, R. (2000) Evaluating impacts of hormonally active agents in the environment. Environ. Sci. Technol. 35:136A-141A.

5.Cooper, R.L. and Kavlock, R.J (1997) Endocrine disruptors and reproductive development; a weight of evidence overview. J. Endocrinol.152:159-166.

6.Karel, A.A.., Manning, S., Brouwer, T.H. and Brouwer, M. (2003) Reproductive effects of estrogenic and antiestrogenic chemicals on sheepshead minnows (Cyprinodon variegatus). Environ. Tox. Chem. 22:855-865.

7.Indarto, D and Izawa, M. (2001) Steroid Hormones and Endocrine disruptors: Recent advances in receptor-mediated actions. Yonago Acta Medica 44:1-6.

8.Babu, T.S., Huang, X. and Greenberg, B.M. (2002) Reactive oxygen species mediated toxicity of environmental contaminants. SETAC Globe 3:26-28.

9.Loaiza-Perez A.I., Seisdedos, M.T., Kleiman de Pisarev, D.L., Sancorich, H.A., Rondi, A.S. and Ferraraola, de-S (1999) Hexachlorobenzene a dioxin-type compound, increase malic enzyme gene transcription through a mechanism involving the thyroid hormones responses element. Endocdrinol.140:4142-4151. 
10.Naz, R.K. (1999) Endocrine disruptors. Effect on male and female reproductive systems. CRC, Boca Raton, FL, USA.

11.Monosson E, Kelcey W.R. Lambright, C., Ostby, J., Gray L. E .Jr. (1999) Peripubertal exposure to the anti androgenic fungicide Vinclozalin, delays puberty, inhibit the development of androgendependent tissues, and alter androgen receptor function in the male rat. Toxicol Ind.Health. 15:65-70

12.Alvarez, L., Randi:, A., Alvarez, P., Piroli, G., Chamson-Reig, A. and Lux-Lantos, V.
(2000) Reproductive effects of hexachlorobenzene in female rats. J. Appl. Toxicol. 20:81-87.

13.Doyle, C. J. and Lim, R. P (2002) The effect of 17B-estraddi on the gonopodia developmeent and sexual activity of Gambusia Holbrook. Environmental Toxicol. Chem. 21: (912):2724

14.Rice, D. C. (1998) Issue in developmental neurotooxicogy: interpretation and implication of the data. Can. J. Pub. Hlth. $89 \quad$ (supl. $\quad$ 1): $5316, \quad 5340$ 